Document downloaded from:

http://hdl.handle.net/10251/93291

This paper must be cited as:

Vidal-Carreras, PI.; García Sabater, JP.; Valero-Herrero, M.; Santandreu Mascarell, C.

(2014). Estimating costs in the EOQ formula. Lecture Notes in Management and Industrial Engineering. 4(1):175-182. doi:10.1007/978-3-319-04705-8_20

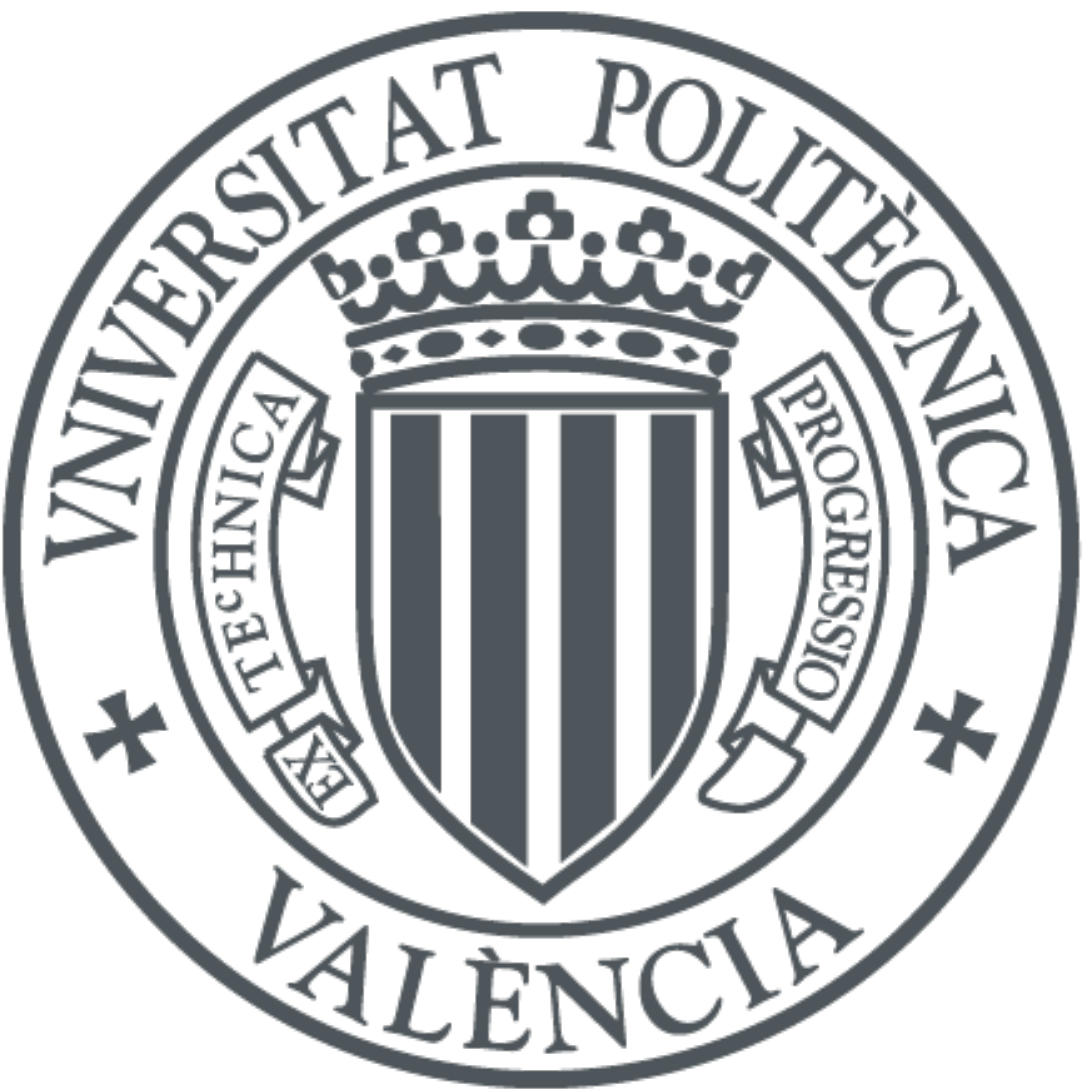

The final publication is available at

http://doi.org/10.1007/978-3-319-04705-8_20

Copyright Springer

Additional Information 


\title{
Estimating costs in the EOQ formula
}

\author{
Vidal-Carreras PI ${ }^{1}$, Garcia-Sabater $\mathrm{JP}^{2}$, Valero-Herrero $\mathbf{M}^{3}$, Santandreu- \\ Mascarell $\mathrm{C}^{4}$
}

\begin{abstract}
The EOQ formula (Harris, 1913) provides a balance between setup costs and holding costs in the system. This formula has been widely developed in the literature. However, in the industrial reality is often difficult to know the exact value of these setup and holding costs. In this paper we develop a formula to estimate the lot size from the known values in the company. It is verified that the behavior of these formulas responds to expectations.
\end{abstract}

Keywords: EOQ, Inventory management, Setup cost, Holding Cost

\section{Introduction}

Defining an inventory management system in a company is to set the technique employed (reorder point management, provisioning theoretical ...) and determine its control parameters. Overall, the control parameters necessary to manage inventory levels are minimum and maximum which would want to keep in the system.

The theoretical resolution of this problem is based on the classic formula EOQ, Economic Order Quantity (Harris, 1913). This formula EOQ provides a balance between setup costs and holding costs in the system. The EOQ model requires

\footnotetext{
${ }^{1}$ Pilar Isabel Vidal Carreras ( $₫$ e-mail: pivicar@omp.upv.es)

Grupo ROGLE. Dpto. de Organización de Empresas. Universidad Politécnica de Valencia. Camino de Vera S/N, 46022 Valencia.

2Jose Pedro Garcia Sabater ( $\bowtie$ e-mail: jpgarcia@omp.upv.es)

Grupo ROGLE. Dpto. de Organización de Empresas. Universidad Politécnica de Valencia. Camino de Vera S/N, 46022 Valencia.

${ }^{3}$ Maria Valero Herrero ( $₫$ e-mail: mavaher@upv.es)

Dpto. de Organización de Empresas. Universidad Politécnica de Valencia. Camino de Vera S/N, 46022 Valencia.

${ }^{4}$ Cristina Santandreu-Mascarell ( $\bowtie$ e-mail: crisanma@omp.upv.es)

Grupo IGIC. Dpto. de Organización de Empresas. Universidad Politécnica de Valencia. Camino de Vera S/N, 46022 Valencia.
} 
know the value of setup costs and holding costs of the products. However, apart from the consideration that all the costs are costs of opportunity, it is that in general and for various reasons, these costs are unknown for companies. Despite this, it is still necessary to establish inventory levels, not as much to optimize the system, but rather to keep it under control.

The EOQ model has been investigated in depth in the literature. For example the topic that it is the joint pricing and inventory optimization. One of the earliest papers on pricing and inventory is by Whitin (1955) who proposes a link between pricing and inventory control. Lee (1993) presents a geometric programming approach to determine a profit-maximizing price and order quantity for a retailer. Most recently, an EPQ inventory model that determines the production lot size, marketing expenditure and product's selling price is developed by Sadjadi et al (2005).

As price is an obvious strategy to influence demand, researching on inventory models with price-dependent demand have been received much attention (You and Chen, 2007) developed an EOQ model of seasonal goods with spot and forward purchase demands Recently, Mo et al (2009) developed an EOQ model with stock and price sensitive demand.

Several researchers have studied the effect of delayed payments on the EOQ. Goyal (1985) was the first to develop a model for a delay in payment to the supplier, making all the usual assumptions of the classic EOQ model except for when payment is due. More recently, Huang (2007) assumed the supplier would offer the retailer a partial delay in payments when the order quantity is smaller than a predetermined quantity. Jaggi et al (2008) proposed a model in which demand is linked to the credit period offered by the retailer to the customers. In Taleizadeh et al. (2013) an EOQ problem under partial delayed payment.

However, about the topic to consider the possible cost estimate of the EOQ formula for a company that does not have them, only papers that assumed that the setup cost is proportional of the time setup and holding cost are proportional to the cost unit but without indicating on which this proportionality is based (Bomberger, 1966; Brander and Segerstedt, 2009; Vidal-Carreras et al., 2012). On the other hand the number of characteristics and variables that are addressed by the models and algorithms has been growing as the computational capacity signal equipment has been developed. And nevertheless, a feature observed, and that is equivalent to that of other authors (Meyer, 2004; Shirodkar and Kempf, 2006) is that most companies are still using Excel spreadsheets for planning, scheduling and controlling their operations. These tools, despite the costs associated with its management manual, appear to be "more effective" in the daily management because they are preferred.

Thus, in the present paper an alternative resolution to the problem of estimating costs for inventory management in the industrial reality is presented. For this, in section 2 the problem to analyze the information typically available in a company is proposed. In section 3 some formulas EOQ's adapted to that information are explained. In section 4, these formulas are integrated into a simple Excel tool and 
their behavior is checked. The conclusions and future works are commented in section 5 .

\section{Statement of the Problem and Notation}

The need to know the setup costs and holding costs can establish difficulties in the actual inventory management systems. While the setup time is available in the companies or otherwise it is easy to measure, to establish a priori setup costs is not. This is so because the cost of setup really is an opportunity cost of use of installed capacity. Similarly, the holding cost is an opportunity cost of the storage capacity available in the company.

Table 1 Notation

\begin{tabular}{cl}
\hline \multicolumn{1}{c}{$\boldsymbol{i}$} & Item index i $=1 . . \mathrm{n}$ \\
\hline$Q_{i}$ & Lot size of item i (units) \\
$d_{i}$ & Demand of item i (units/unit of time) \\
$c a_{i}$ & Holding cost of item i (monetary units) \\
$c s_{i}$ & Setup cost of item i (monetary units) \\
$t s_{i}$ & Setup time of item i (time units) \\
$\eta_{i}$ & Density of Value of item i (monetary units / packaging units) \\
$p e_{i}$ & Pallet equivalent of item i (monetary units/pallet) \\
\hline
\end{tabular}

In order to analyze clearly the problem is considered appropriate to focus on the case of a machine of a manufacturer of goods. The machine required for each change of production run needs a preparation, which consumes time and resources. To make the change (setup) workers are available to prepare the machine for the production but the company does not know the cost associated with this setup. It can approximate this setup cost is proportional to the setup time (Bomberger, 1966). The notation used in the sequent sections is shown above in Table 1.

Regarding the holding cost of each product, it is not possible to define it a priori. The companies usually have a limited storage capacity and also a cash limit that they are willing to maintain. Each product has specific characteristics of both economic value and volume taken. If the financial constraint of the company is important, it can be assumed that the costs associated with storage are proportional to the amount of money in stock or equivalently, the unit cost of the products. If the limitation of space in the company is important, one can assume that storage costs are proportional to the number of locations used, which for example may count the number of pallets used for each product. In both situations, as mentioned, these storage costs are not known at the exact value in the company. Thus, 
generally in the actual practice of the company, the different departments involved establish a maximum limit of storage, around which usually the inventory policies are defined.

\section{A method of calculating costs}

According to the classical EOQ of formula (Harris, 1913), shown in (4.1), the calculation of the economic lot manufacture of a product $i$, considering its demand $\mathrm{d}_{\mathrm{i}}$, requires consideration of a series of costs. On the one hand, it has been considered a cost of setup, $c s_{i}$, in relation to change of production run, which is the process of preparing the machinery for the production of product i. On the other hand, a holding cost of product i manufactured, $\mathrm{Ca}_{i}$ :

$$
Q_{i}=\sqrt{\frac{2 d_{i} c s_{i}}{c a_{i}}}
$$

However, as discussed in the industrial reality is not always known the value of this cost of this setup and holding cost required in formula (4.1). Regarding the setup, so if time is generally known, $\mathrm{ts}_{\mathrm{i}}$. So it is appropriate to assume that the cost of setup, $\mathrm{cs}_{\mathrm{i}}$, will be proportional to the time of setup $\mathrm{ts}_{\mathrm{i}}$ according to a proportionality constant that we will call cs, and whose units are ( monetary units / units of time):

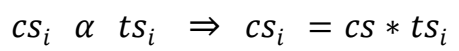

The company should establish the value of the constant cs according to the value of the time spent by operators in the setup. If a company has highly automated processes in which the workers only have direct participation in the process for a specific fraction of time, this constant cs may have a very low value because it has idle manpower for a period of time. On the contrary if a company demands high manpower requirement or if this is very scarce, the value should be higher cs. This constant cs is independent of the products and only depends on the characteristics of the company.

Regarding the holding cost, $c a_{i}$, that appears in formula (4.1) also it is not an exact data. However as mentioned it can be assumed that its value is proportional to the unit cost of the product, the volume taken for the product in the warehouse or the combination of both variables. It will develop the alternatives.

Firstly, the holding cost may be proportional to $c u_{i}$ according to a proportionality constant that we can call $c a_{1}$ :

$$
c a_{i} \quad \alpha \quad c u_{i} \Rightarrow c a_{i}=c a_{1} * c u_{i}
$$

The company should set the value of the constant $c a_{1}$ depending on financial conditions they have. For example if the company has a mortgage loan with a high interest rate constant should have a high value. Similarly happen if the goods are 
perishable stocks. The constant value of $c a_{1}$ is usually different in the life cycle of companies.

For the case where the cost is proportional to the storage space taken by the product, there is a constant proportional named $c a_{2}$. To pose the volume of the product is defined the variable pallet equivalent, $p e_{i}$. This variable indicates what percentage of the pallet occupies a unit volume of product. This value is known in company as they know the number of product units that fit on a pallet. In the case that the storage unit is outside the pallet employ different reference that storage unit. So the holding cost is proportional to the space taken by the products, there is a constant proportional named $\mathrm{ca}_{2}$. This is appropriate to assume that the cost of storage $\mathrm{ca}_{\mathrm{i}}$ will be proportional to the pallet equivalent $p e_{i}$ according to a proportionality constant $c a_{2}$ and whose units are (monetary units / pallet).

$$
c a_{i} \alpha p e_{i} \Rightarrow c a_{i}=c a_{2} * p e_{i}
$$

But besides the holding cost should be considered inversely proportional to the density value (4.5). The density value is called $\eta_{i}$, and it is defined as the monetary units included in each pallet equivalent (4.5). It is easy to get a variable in the company knowing units per pallet and the cost of these.

$$
\begin{aligned}
c a_{i} 1 / \alpha \quad \eta_{i} & \Rightarrow c a_{i}=c a_{2} / \eta_{i} \\
\eta_{i} & =\frac{c u_{i}}{p e_{i}}
\end{aligned}
$$

Thus combining (4.4) and (4.6) the following formula for the case where the cost is proportional to the storage space taken by the products are obtained (4.7):

$$
c a_{i}=\beta c a_{2} \frac{p e_{i}}{\eta_{i}}
$$

In order to include both the consideration that the cost is proportional to the storage unit cost of products (4.3) and the space occupied by the same (4.7) the following formula (4.8) is defined:

$$
c a_{i}=\alpha c a_{1} c u_{i}+\beta c a_{2} \frac{p e_{i}}{\eta_{i}}
$$

Through this formula the various combinations of storage costs in the company are represented. The variable $\alpha$ represents the weight of the financial condition of the company, and the weight of $\beta$ represents the volume restrictions in the store. Since it is a combination of both, the sum of variables $\alpha$ and $\beta$ is according to:

$$
\alpha+\beta \leq 2
$$

These $\alpha$ and $\beta$ provide flexibility for the system in specific situations without the need to rethink the value of $c a_{1}$ and $c a_{2}$. If the value of setup costs (4.2) and the value of the holding costs (4.8) are included in the lot size formula (4.1) the result is (4.10):

$$
Q_{i}=\sqrt{c s} \sqrt{\frac{2 d_{i} t s_{i}}{\alpha c a_{1} c u_{i}+\beta c a_{2} \frac{p e_{i}}{\eta_{i}}}}
$$


It is a formula that allows for the lot size of a product from the company known variables such as product demand, unit cost, and its equivalent pallet setup time required for its production. The company should set the value of the constants $c s, c a_{1}, c a_{2}, \alpha$ and $\beta$ cs, that are common to all products and allow adjusted to the different circumstances. For example if the company warehouse is full is expected to increase storage costs associated with the volume, this is the constant $\alpha c a_{2}$. But if the store was empty, the financial criteria would overlap and should increase the value of the variable $\beta c a_{2}$.

At this point the value of the lot size for specific circumstances is posed:

- If only attach importance to the financial limitations of the company and space constraints would not supposed $\beta=0$ so that would not be necessary to specify the value of the constant $\mathrm{ca}_{2}$, leaving the lot size formula as:

$$
Q_{i}=\sqrt{c s} \sqrt{\frac{2 d_{i} t s_{i}}{\alpha c a_{1} c u_{i}}} \Rightarrow Q_{i}=\frac{\sqrt{c s}}{\sqrt{\alpha c a_{1}}} \sqrt{\frac{2 d_{i} t s_{i}}{c u_{i}}}
$$

- If only considered important space limitations in the company and had no significant financial constraints, it is assumed $\alpha=0$, so that would not be necessary to specify the value of the constant $\mathrm{ca}_{1}$, leaving the lot size formula as (4.12):

$$
Q_{i}=\sqrt{c S} \sqrt{\frac{2 d_{i} t s_{i}}{\beta c a_{2} \frac{p e_{i}}{\eta_{i}}}} \Rightarrow Q_{i}=\frac{\sqrt{c S}}{\sqrt{\beta c a_{2}}} \sqrt{\frac{2 d_{i} t s_{i}}{\frac{p e_{i}}{\eta_{i}}}}
$$

\section{Analysis of the Behavior of the Formulas}

The formulas exposed are supported on an Excel spreadsheet. Thus from introducing known values are obtained the lot sizes, as it is shown in Table 2.

\begin{tabular}{|c|c|c|c|c|c|c|c|}
\hline \multicolumn{7}{|l|}{ Data } & \multirow[t]{4}{*}{ Result } \\
\hline alpha & & ca1 (€/€day) & 0,00042 & & & & \\
\hline \multirow[t]{2}{*}{ beta } & & ca2(€/palletdía) & 0,2 & & & & \\
\hline & & $\operatorname{cs}(€ /$ hour) & 4 & & & & \\
\hline Item & $\begin{array}{l}\text { Demand } \\
\text { (uds/day) }\end{array}$ & Unit cost $(€)$ & $\begin{array}{c}\text { Setup } \\
\text { Time } \\
\text { (hour) }\end{array}$ & Units per pallet & $\begin{array}{c}\text { Equivalent } \\
\text { Pallet }\end{array}$ & $\begin{array}{l}\text { Value of } \\
\text { Density }\end{array}$ & Lot Size \\
\hline i & di & cui & tsi & udi/palet & pei & ni & Qi \\
\hline 1 & 100 & 5 & 3 & 100 & 0,010 & 500 & 1072,28 \\
\hline 2 & 150 & 4 & 1 & 150 & 0,007 & 600 & 847,96 \\
\hline 3 & 200 & 3 & 1 & 200 & 0,005 & 600 & 1130,62 \\
\hline 4 & 250 & 2 & 1,5 & 250 & 0,004 & 500 & 1895,55 \\
\hline
\end{tabular}

Table 2 Numerical example 


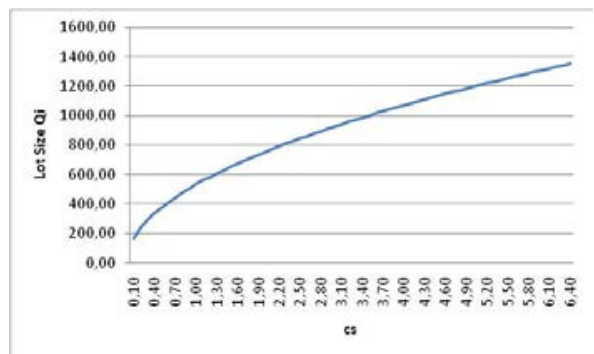

(a)

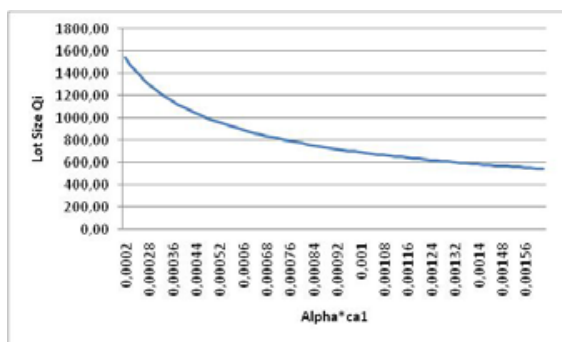

(b)

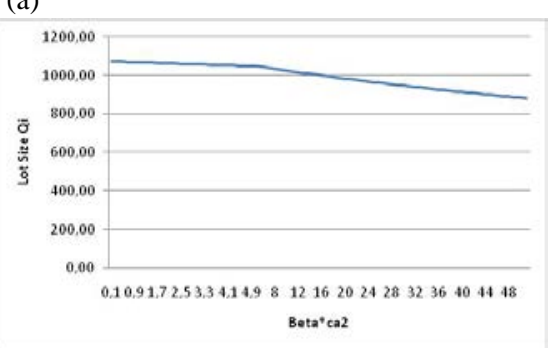

(c)

Fig. 1 Evolution of the lot size according to (a) $c s$, (b) $\alpha c a_{1}$ and (c) $\beta c a_{2}$

It is analyzed the behavior of the formula 4.10 to be the most complete, for an item, particularly item 1 of Table 2. Fig 1 shows the evolution of the lot size of this item varying the different costs. Fig 1 (a) shows the growth of the lot size by increasing the variable $c s$, as this is an increase in costs associated with the setup for example restrictions on manpower. Fig 1 (b) shows the decrease in lot size to increase the variable $\alpha c a_{1}$. This decrease is suitable for the variable $\alpha c a_{1}$ affected part of the holding cost. Fig 1 (c) shows much slower decrease in lot size of the variable increasing $\beta \mathrm{ca}_{2}$ It is to be considered that in formula holding cost associated with volume restrictions has also considered its relationship with the density value so its contribution in the formula is smaller. That is why it is necessary to greatly increase the value of $\beta c a_{2}$ to observe the expected decrease lot size. In the case that in the formula 4.10 not considered density value and only the space occupied by the products through the variable $p e_{i}$, the behavior of the formula against $\beta \mathrm{Ca}_{2}$ small variations will be very similar that is shown in Fig 1. (c).

\section{Conclusions}

In this work, the classical formula EOQ of Harris (1913) is adapted to the industrial reality, in which it is often complex to have cost values of setup and holding. We propose simple formulas for the costs which can obtain these setup costs and storage company based on values if known therein. So, it could define costs that 
can easily be interpreted as having a meaning. How it has developed in the section on behavior analysis of these formulas is as expected. The following work would consist in integrating these formulas in a inventory-tool that could take more considerations that exist in companies, such as: the available capacity, the average level of warehouse that is desired, the average level of inventory, the inventory limits maximum and minimum which are consider for some products... This tool should allow to define final lot sizes considering all the constraints and from these lot size define the maximum and minimum levels for each product.

Agreements: The work described in this paper has been supported by the project "CORSARI MAGIC DPI2010-18243" by the Ministerio de Ciencia e Innovación del Gobierno de España.

\section{References}

Bomberger, E. E. (1966). A dynamic programming approach to a lot size scheduling problem. Management Science, Vol. 12, No. 11, p. 778.

Brander, P.; Segerstedt, A. (2009). Economic lot scheduling problems incorporating a cost of using the production facility. International Journal of Production Research, Vol. 47, No. 13, pp. 3611-3624.

Goyal, S. K. (1985). Economic order quantity under conditions of permissible delay in payments. Journal of the Operational Research Society, Vol. 44, pp. 785-795.

Harris, F. W. (1913). How many parts to make an once. Factory, The Magazine of Management, Vol. 10, No. 2, pp. 135-6-152.

Huang, Y. F. (2007). Economic order quantity under conditionally permissible delay in payments. European Journal of Operational Research, Vol. 176, No. 2, pp. 911-924.

Jaggi, C. K.; Goyal, S. K.; Goel, S. K. (2008). Retailer's optimal replenishment decisions with credit-linked demand under permissible delay in payments. European Journal of Operational Research, Vol. 190, No. 1, pp. 130-135.

Lee, W. J. (1993). Determining order quantity and selling price by geometric programming: Optimal solution, bounds, and sensitivity. Decision Sciences, Vol. 24, No. 1, pp. 76-87.

Meyer, B. (2004). Value-adding logistics for a world assembly line Bonifatius Verlag, Paderborn

Mo, J.; Mi, F.; Zhou, F.; Pan, H. (2009). A note on an EOQ model with stock and price sensitive demand. Mathematical and Computer Modelling, Vol. 49, No. 9, pp. 2029-2036.

Sadjadi, S. J.; Oroujee, M.; Aryanezhad, M. B. (2005). Optimal production and marketing planning. Computational Optimization and Applications, Vol. 30, No. 2, pp. 195-203.

Shirodkar, S.; Kempf, K. (2006). Supply chain collaboration through shared capacity models. Interfaces, Vol. 36, No. 5, pp. 420-432.

Taleizadeh, A. A.; Pentico, D. W.; Saeed Jabalameli, M.; Aryanezhad, M. (2013). An EOQ model with partial delayed payment and partial backordering. Omega, Vol. 41, No. 2, pp. 354368.

Vidal-Carreras, P. I.; Garcia-Sabater, J. P.; Coronado-Hernandez, J. R. (2012). Economic lot scheduling with deliberated and controlled coproduction. European Journal of Operational Research, Vol. 219, No. 2, pp. 396-404.

Whitin, T. M. (1955). Inventory control and price theory. Management Science, Vol. 2, No. 1, pp. 61-68.

You, P. S.; Chen, T. C. (2007). Dynamic pricing of seasonal goods with spot and forward purchase demands. Computers and Mathematics with Applications, Vol. 54, No. 4, pp. 490-498. 